\title{
EVALUATION OF TANK MIX ADJUVANTS AND NOZZLES FOR AGRICULTURAL SPRAYS
}

\author{
A.J. HEWITT \\ Stewart Agricultural Research, P.O. Box 509, Macon, MO, USA
}

\begin{abstract}
Studies have been conducted to measure the effects of different surfactant, crop oil and drift control adjuvants on spray characteristics and drift for glyphosate. Three types of nozzle were used: flat fan, disc-core and air induction. Spray formation was investigated using spark photography to study the breakup of the liquid sheets into droplets and assess spray angle. Droplet size spectra were measured using laser instruments. Dynamic surface tension and extensional viscosity were measured for each tank mix for comparison with atomization characteristics. A linear patternator was used to measure the liquid distribution patterns. Drift potential was measured in a wind tunnel using horizontal and vertical collector lines to assess deposition and airborne drift risk respectively. The different adjuvants and nozzles had different effects on spray formation and drift. The polymer products tended to decrease the drift potential of the glyphosate, but also caused the droplet size spectra to become more polydisperse; to narrow the sheet angle and thereby affect liquid distribution uniformity; and to break down when subjected to pumping representative of agitation under field use conditions. The surfactants caused mixed results upon spray formation and drift potential, depending on the specific chemistry. Invert suspension adjuvants tended to improve the spray quality, liquid distribution uniformity and decrease the drift potential of glyphosate.
\end{abstract}

